\title{
Highly Loaded Composite Strut Test Development
}

\author{
K. Chauncey $\mathrm{Wu}^{*}$ \\ NASA Langley Research Center, Hampton, VA 23681 \\ James E. Phelps ${ }^{\dagger}$ and Martin J. McKenney ${ }^{\ddagger}$ \\ ATK Space Systems, Inc., Hampton, VA 23681 \\ and \\ Dawn C. Jegley ${ }^{\S}$ \\ NASA Langley Research Center, Hampton, VA 23681
}

\begin{abstract}
Highly loaded composite struts, representative of structural elements of a proposed truss-based lunar lander descent stage concept, were selected for design, development, fabrication and testing under NASA's Advanced Composites Technology program. The focus of this paper is the development of a capability for experimental evaluation of the structural performance of these struts. Strut lengths range from 60 to over 120 inches, and compressive launch and ascent loads can exceed $-100,000 \mathrm{lbs}$, or approximately two times the corresponding tensile loads. Allowing all possible compressive structural responses, including elastic buckling, were primary considerations for designing the test hardware.
\end{abstract}

\section{Introduction}

Long beam-columns, or struts, have many applications in aerospace structures. Applications include supports for deployable antennas or solar panels, components for lunar lander spacecraft (Figure 1) and surface systems, strut-braced wing components or aircraft spars. Slender struts have been used for deployable or erectable parts of a space station truss, large space telescope support trusses, and solar array trusses where dimensional tolerance and thermal response can be critical. Therefore, NASA has a continuing interest in both improving and experimentally verifying the loadcarrying capability of these types of structural components to support the goal of designing highperformance, lightweight aerospace structures. The Advanced Composites Technology (ACT) program ${ }^{1}$ was started in 2008 to develop and advance the Technology Readiness Level of selected composite structures

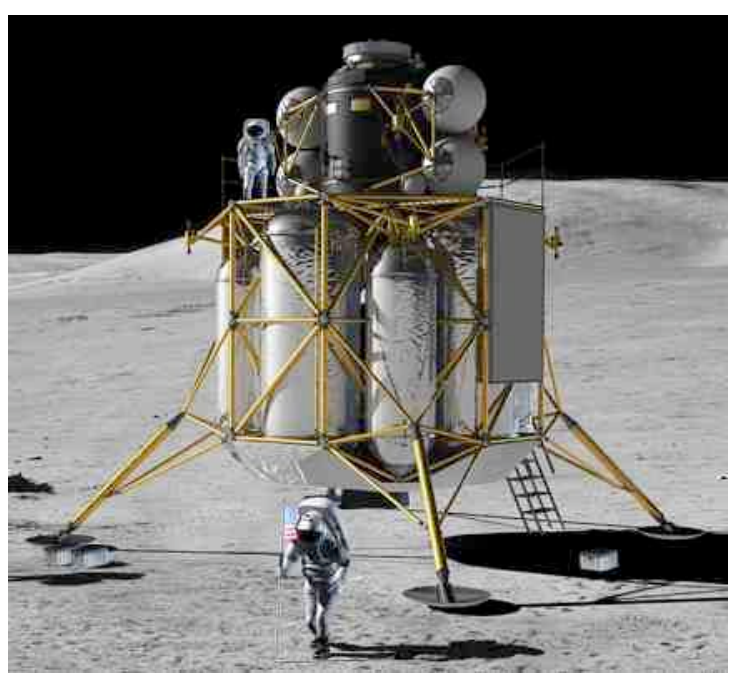

Figure 1. Altair lunar lander concept.

\footnotetext{
* Senior Aerospace Engineer, Structural Mechanics and Concepts Branch, RD, MS 190.

${ }^{\dagger}$ Senior Design Engineer, Structural Dynamics Branch, RD, MS 230.

Design Engineer IV, Structural Dynamics Branch, RD, MS 230.

$\S$ Senior Aerospace Engineer, Structural Mechanics and Concepts Branch, RD, MS 190, AIAA Associate Fellow.
} 
and technologies for the Constellation program.

The Altair lunar lander project was identified as a customer for a portion of the ACT program. ${ }^{2}$ Since the vehicle mass launched from earth is typically several hundred times larger than the portion landed on the moon, this high "gear ratio" demands that the structure and its components have the minimum mass necessary to satisfy the requirements (i.e., high structural efficiency). Composite materials and nontraditional manufacturing techniques offer opportunities for reducing the mass of struts when compared to using conventional aluminum tubes with uniform circular cross-sections. Discussions with the Altair project led to selection of highly loaded composite struts for an advanced technology development activity performed under the ACT program.

Structural analyses of a proposed Altair lunar lander ${ }^{3}$ descent stage truss, shown in Figure 1, were

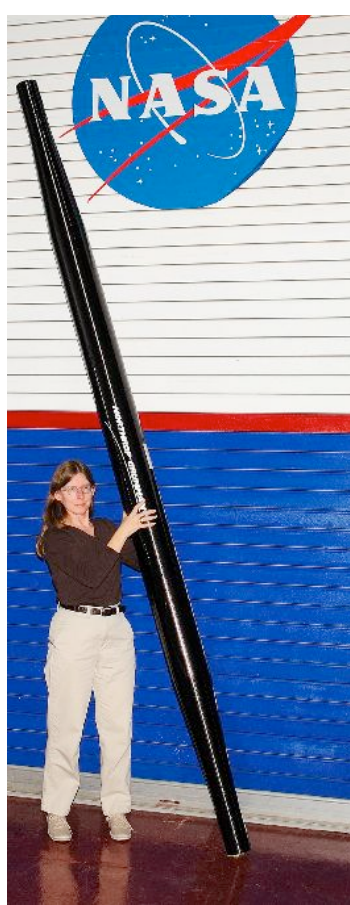

2a. Long strut. performed to predict tensile and compressive strut loads during launch, ascent, translunar injection and lunar landing. ${ }^{4}$ The 200 struts in the lander descent stage structural configuration were collected into 30 member groups based on similar lengths and loads. The predicted strut compressive design ultimate loads (DULs) of up to $-107 \mathrm{klb}(1 \mathrm{klb}$ equals $1000 \mathrm{lbs})$ were typically much greater than the corresponding $60 \mathrm{klb}$ tensile DULs. The strut design limit loads (DLLs) were calculated by dividing the DULs by a safety factor of 1.4. These design loads were provided to several contractor teams who designed, analyzed and built five heavily-loaded composite struts, ${ }^{5-6}$ which were then delivered to NASA for testing. Three additional struts, shown in Figure 2, were built by the contractors as manufacturing demonstration units ${ }^{7-8}$ during the first phase of this study. ${ }^{2}$ The larger, 127 inch-long strut (Figure 2a) had a predicted buckling load of approximately $-140 \mathrm{klb}$, and the two smaller, 61 inch-long struts (Figure 2b) had predicted buckling loads of about $-25 \mathrm{klb}$. One contractor also built two struts that were designed for low buckling loads of approximately $-2 \mathrm{klb} .^{8}$

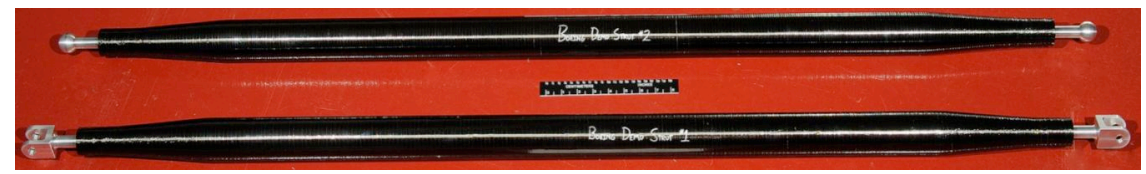

2b. Short struts.

Figure 2. Composite struts.

The objective of this paper is to describe the hardware and methodology developed primarily to perform tension and compression tests on heavily loaded composite struts. Preliminary compression test results for the three struts shown above are presented and discussed here. An overview of the design, optimization, and analysis studies for heavily loaded composite struts performed under NASA's ACT program is given in Ref. 2. Test results for the other seven composite struts developed and evaluated under this activity are presented in Refs. 9 and 10.

\section{Test Facility Requirements}

The critical requirements for the test facility necessary for successful implementation of the strut test program are presented in this section. A key element was that the facility would be capable of readily accommodating struts with lengths from 60 to over 120 inches, and applied compression loads up to -150 $\mathrm{klb}$, with minimal hardware modifications. The associated test fixture and hardware must be stiff to minimize their movement and deflection during testing, and prevent introduction of spurious moments in the load path. They must also be adjustable to allow proper vertical alignment of the strut, ensuring that the strut axis is parallel to gravity.

Because the lander struts will experience both tensile and compressive loads in service, they must also be tested under both loading conditions. To simplify testing, the same test fittings should be used to 
connect the strut to the test facility for loading in either direction. In addition, these test fittings should provide for quick and easy assembly and installation of the strut, and allow for rapid positioning of test instrumentation needed to measure the strut structural response.

Since compressive loads dominate the structural response, identification of the correct compressive failure mode, possibly including structural stability, was of primary concern during the tests. Assuming no material-strength failures, elastic Euler buckling ${ }^{11}$ (where a strut with pinned end conditions deforms into a half-sine wave mode shape), represents a conservative lower bound for the load-carrying capability of an individual strut within a built-up truss structure. Therefore, the strut ends must be able to rotate freely without applied moments or translation, thus replicating the simply supported boundary conditions necessary for Euler buckling.

\section{Test Fitting Development}

Several options were considered for the test fittings that interface between the contractor-provided composite struts and the test facility. These test fittings must be able to satisfy the requirements described in the previous section. Among the options considered, cup/cone end fittings ${ }^{12}$ are simple and provide good experimental pinned-end boundary conditions for compressive loading, but cannot carry tensile loads. Single degree-of-freedom rotational hinges ${ }^{13}$ allow both tensile and compressive loading, but also require careful alignment to ensure that column buckling occurs in a plane perpendicular to the plane containing the hinge axes at each end of the strut. In addition, any initial geometric imperfection in the strut must be oriented normal to the hinge plane for proper measurement of the minimum buckling load, which may not be practicable during the test. Also, relative alignment (both spatial and rotational) of the upper and lower hinges is very important for this concept to be successfully implemented. Coupler bearings were used for the tension tests of Ref. 14, but none of this type were found that were capable of supporting both the current anticipated tension and compression loads. In addition, determination of the center of rotation (and resulting overall strut length for Euler buckling calculations) of the coupler bearing is not straightforward.

Further consideration of these options led to selection of commercial, high load-capacity rod end bearings with an internal spherical bearing and supporting race (Figure 3) for development as test fittings. The threaded studs on these test fittings were then machined to match the threads inside the composite strut ends, and a jam nut (shown in the figure) was used to prevent their relative motion. These test fittings allowed free rotation in three orthogonal axes about a common point (the spherical bearing center), while also preventing translation of that point. Because they do not constrain free rotation of the strut ends, these test

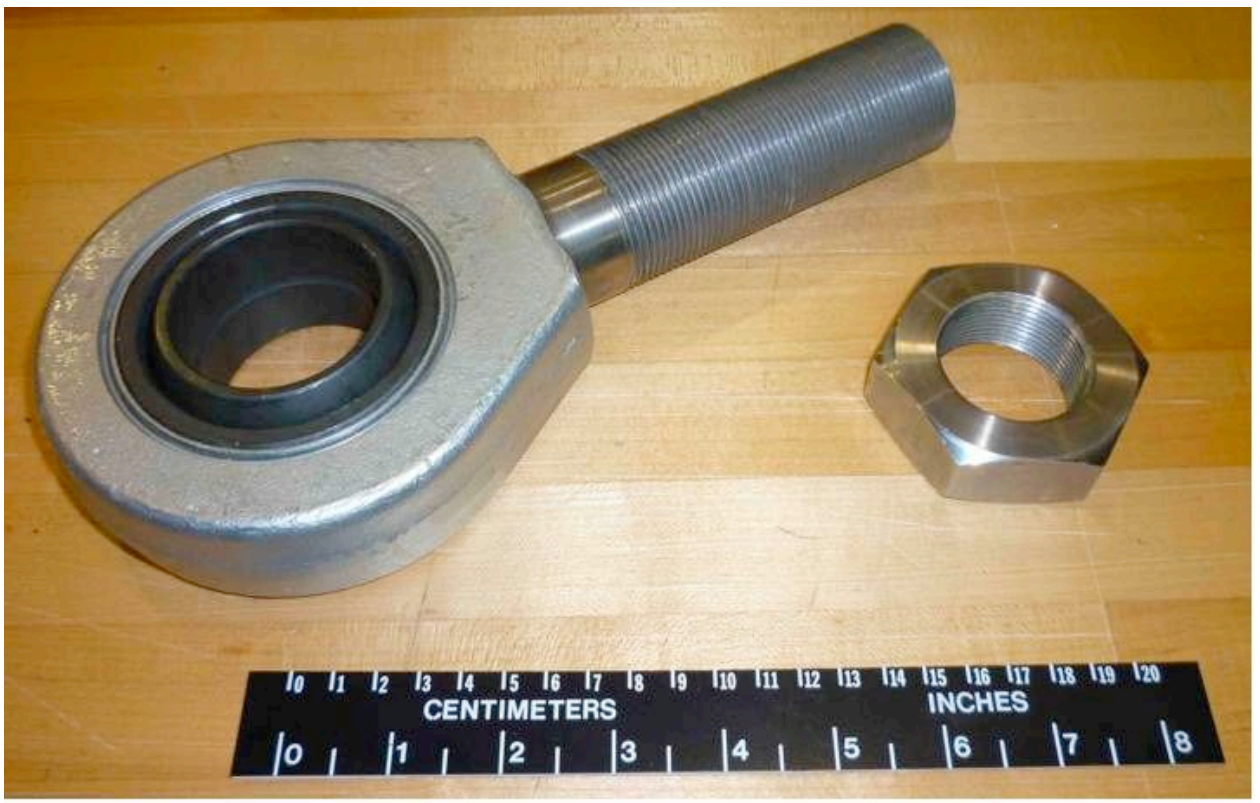

Figure 3. Rod end bearing test fitting.

fittings should be insensitive to alignment of the strut geometric imperfection, as well as any rotational misalignment between the upper and lower strut ends. Since the strut was loaded through applying an 
axial displacement to its lower end during the test, these test fittings should be usable in either load direction, with minimal mechanical free-play.

To interface with the rest of the test facility, each test fitting was then connected to two, 1 inch-thick steel vertical clevis plates with a large, 2 inchdiameter steel pin, forming a doubleshear, tang-and-clevis joint. These two clevis plates were then bolted to a 1 inch-thick horizontal base plate that was bolted to the rest of the test facility. To keep the test fitting centered in the clevis, steel spacers were added on either side of the test fitting to limit its lateral motion, while still allowing it to rotate

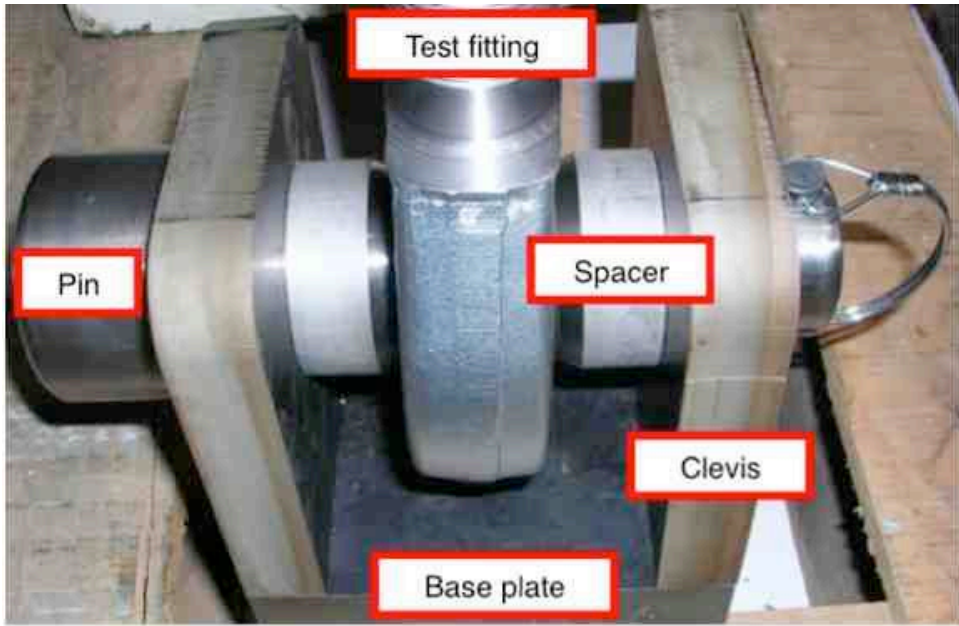

Figure 4. Test fitting and clevis assembly. on the spherical bearing. A complete test fitting and lower clevis assembly is shown in Figure 4. Removal of the pins and spacers allowed quick removal of the strut from the test facility, with installation performed by reversing this operation.

\section{Test Facility Development}

The primary features of the test facility are the backstop, the actuator, the load cells, the support brackets, and the test fittings described above. These elements are shown in Figure 5, and are described in more detail in this section. Details of the lower and upper ends of the test facility with an installed composite strut are shown in Figures 6a and 6b, respectively. Also shown in Figure 6 are the linear variable differential transformers (LVDTs) and strain gages used to monitor the structural response of each strut during the tests. A visual image correlation system was also used for this purpose.

The test hardware was mounted to a stiff, steel backstop to react the loads applied to the composite struts. This permanent backstop was tall enough to accommodate the entire range of strut lengths. T-slots, evenly spaced on 3-inch centers and seen in Figures 5 and 6 as the black horizontal lines, allowed great flexibility in positioning the test hardware. T-nuts (Figure 7a) were placed into the T-slots, and stock bolts were threaded into the T-nuts to attach the various components, as shown in Figure $7 \mathrm{~b}$.

A large $225 \mathrm{klb}$-capacity hydraulic actuator with a 12-inch stroke, shown in Figure 8, was used to apply axial loads to the heavily loaded struts. This actuator was originally selected because it could pivot around the center of its lower mounting hardware in a plane normal to the backstop, and also pivot from left to right by \pm 5 degrees. However, the actuator could not rotate a full 90 degrees around its own mounting hardware in the plane normal to the backstop, which precluded mounting it

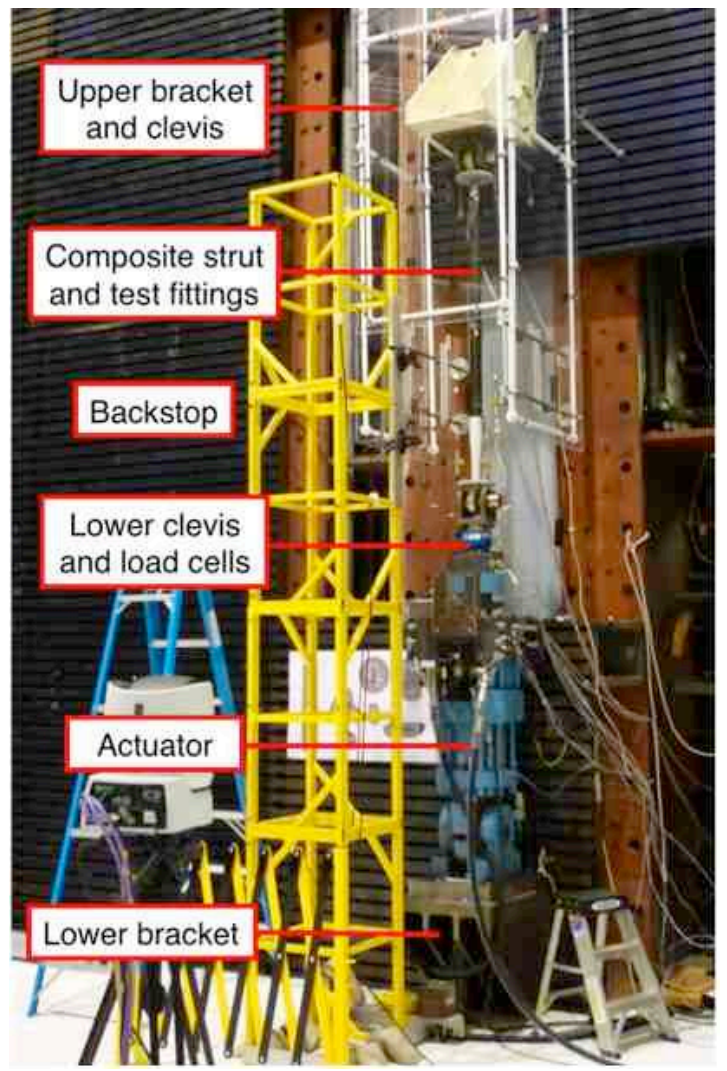

Figure 5. Strut test facility. 
directly to the backstop as originally planned. The actuator was instead bolted to a stiff steel lower bracket, which was then bolted to the backstop using 18 socket head cap screws and T-nuts. A steel support post was also installed between the lower bracket and the concrete floor for additional support, and was then shimmed to ensure full contact with the floor of the building.

To test the lightly loaded struts discussed in Refs. 8 and 9, the hand-operated hydraulic actuator shown in Figure 9 was installed, replacing the large actuator in Figure 8. This much smaller system could apply axial forces to the struts of up to $10 \mathrm{klb}$ in either tension or compression. Except for some additional supports used to prevent undesirable rotation or translation of the lower clevis and actuator, the structural elements used during the lightly loaded strut tests were identical to those developed for the heavily loaded strut tests described herein.

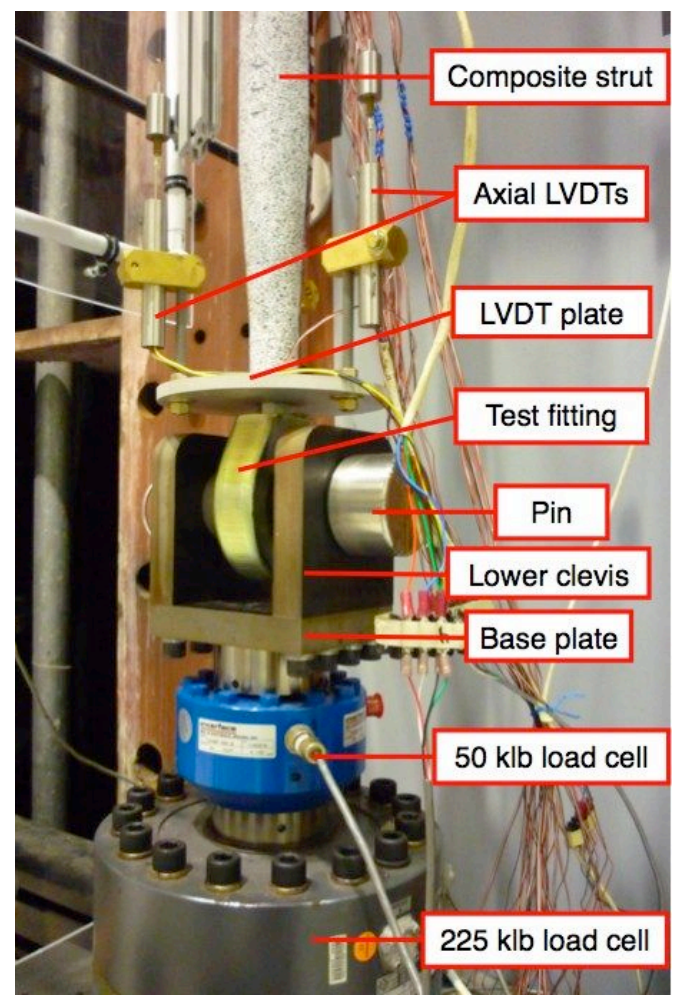

6a. Lower strut details.

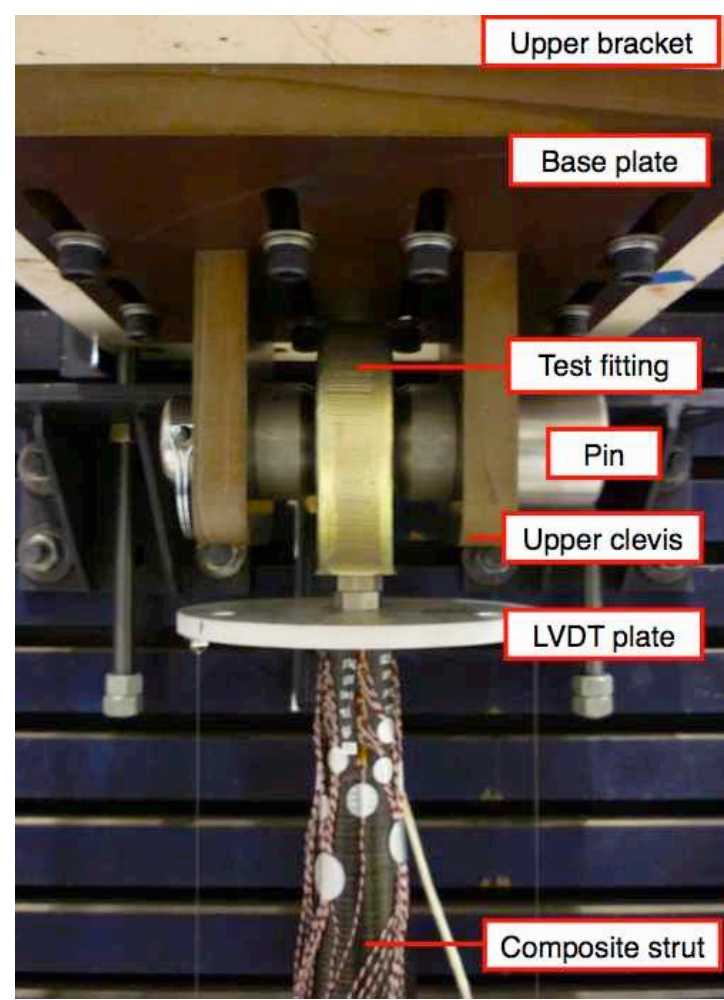

6b. Upper strut details.

Figure 6. Test facility hardware details.

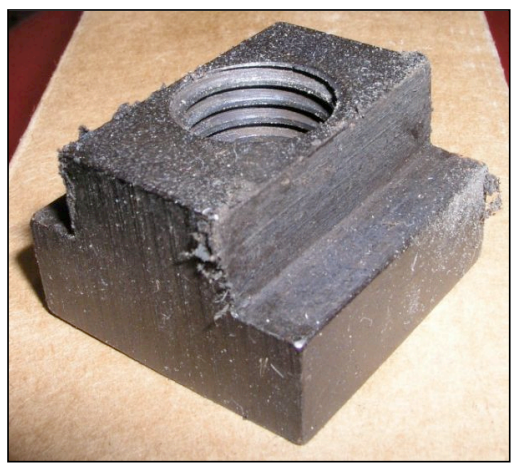

7a. T-nut hardware.

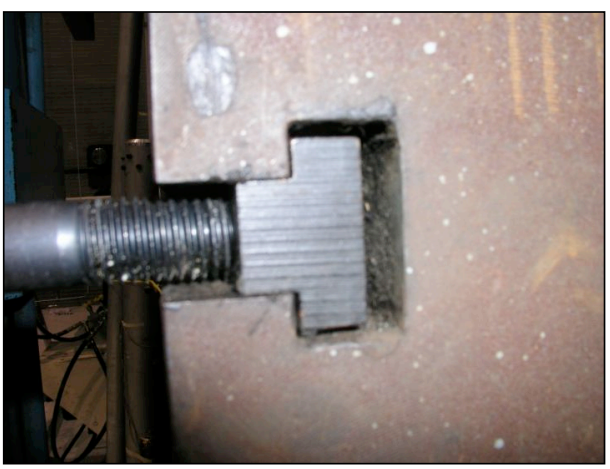

7b. T-nut and bolt in T-slot.

Figure 7. Backstop attachment hardware. 


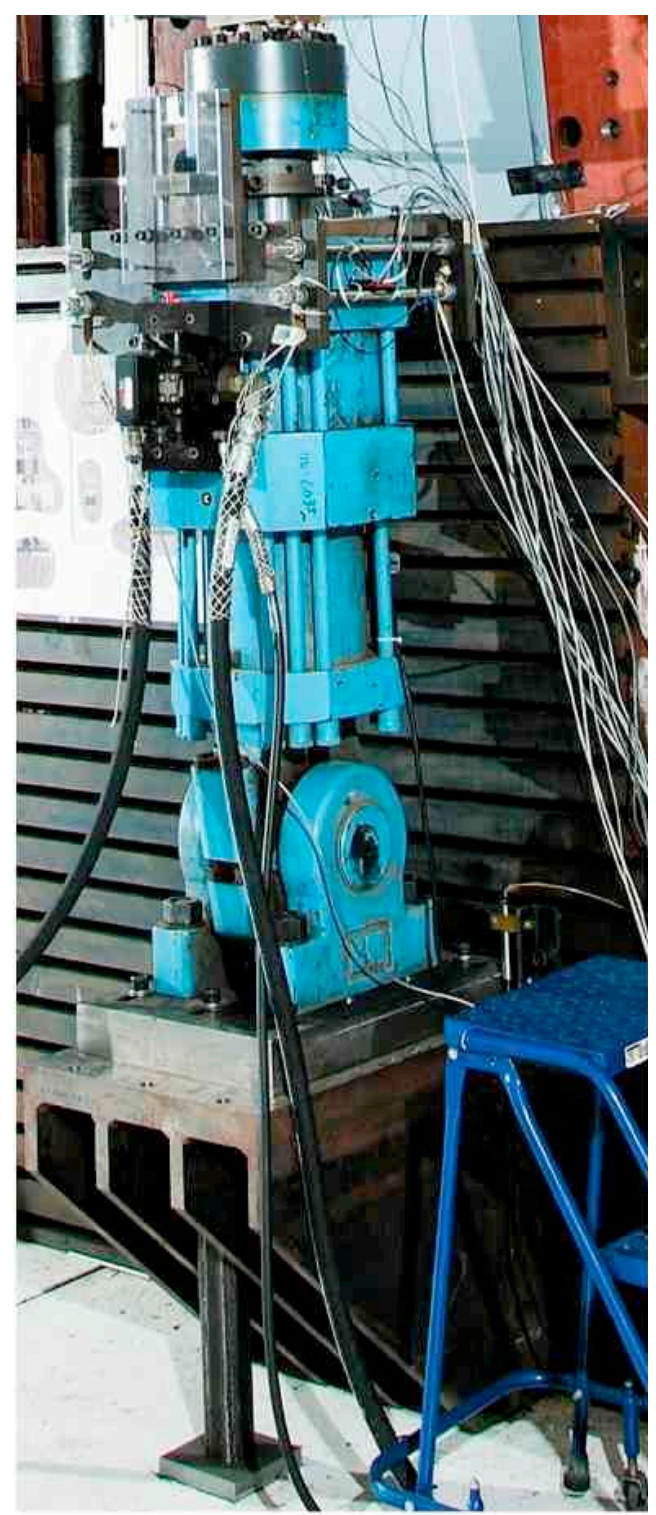

Figure 8. 225-klb hydraulic actuator and lower bracket.

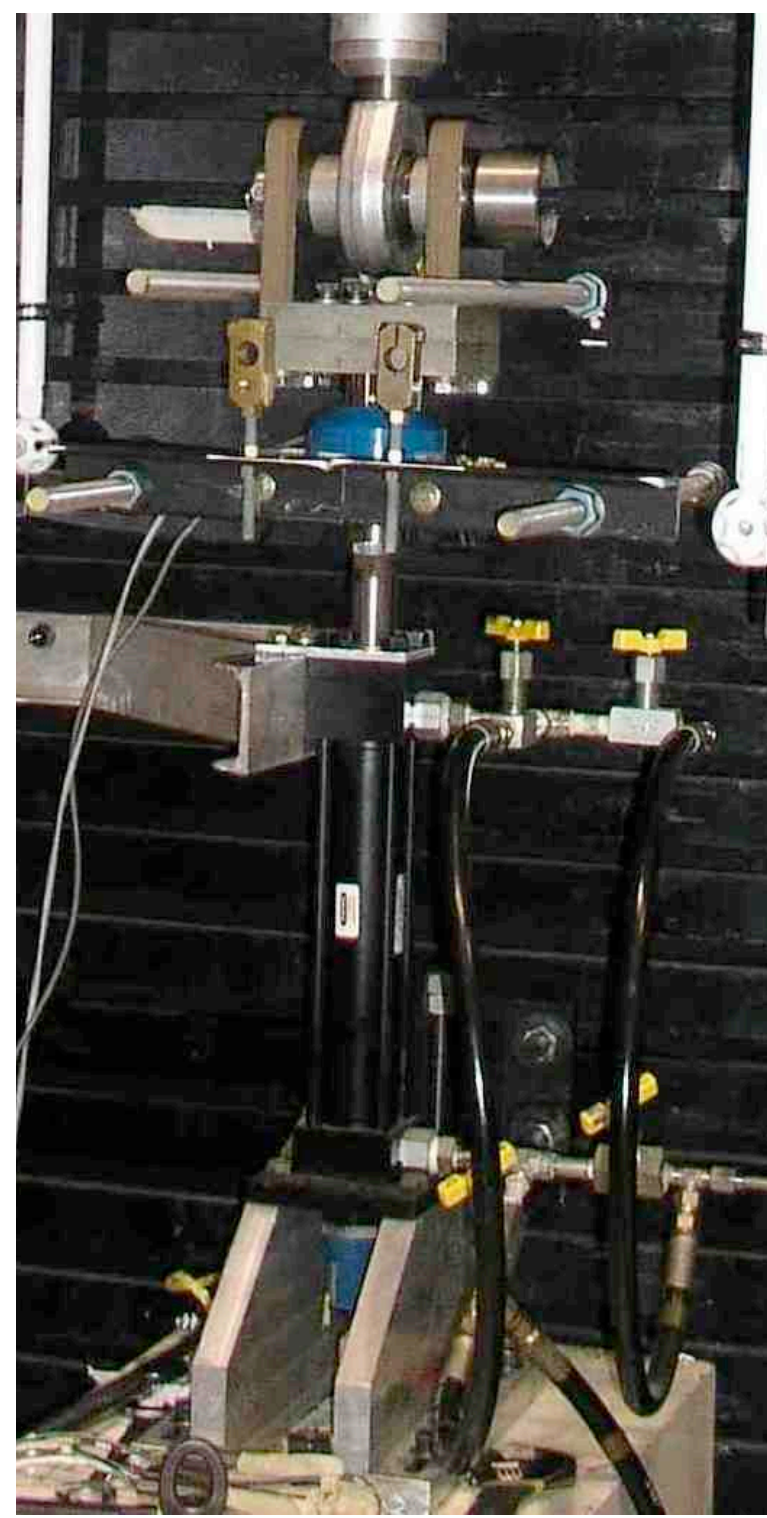

Figure 9. Hand-operated hydraulic actuator for lightly loaded strut tests.

To first allow for alignment of the actuator with the backstop and test facility, and then to prevent any unwanted movement, the support hardware shown in Figure 10 was designed and fabricated. Since the actuator had no built-in hardware mounting points, 1 inch-thick steel plates were used to capture the actuator and restrain its motion. Front and back plates were bolted to a top plate, which was fitted around the upper ring of the actuator. Shims were used to prevent any movement of the actuator relative to the top plate. A digital level, positioned on the face of the actuator piston, was then checked as the actuator was moved to several different positions. This verification was done to ensure that the actuator piston face was horizontal, and therefore that the actuator piston was vertical, over its full stroke. After the actuator was correctly positioned, jam nuts on threaded rods were used to lock the front and back plates in place, and an angle bracket was bolted to both the backstop and the top plate. 
Two separate load cells were installed to accommodate the different load ranges anticipated for the tests. A small, $50 \mathrm{klb}$ capacity temporary load cell was used to monitor the axial load in struts with lower failure loads, and the permanently installed 225 klb-capacity load cell was used to monitor the load applied to struts designed to support higher loads. For tests at lower loads, the lower clevis and small, 50-klb load cell were connected in series to the large, 225-klb load cell using two threaded adapters, as shown in Figure 6a. When the heavily loaded struts were tested, the $50-\mathrm{klb}$ load cell was removed to prevent it from being damaged, and the lower clevis was attached directly to the 225-klb load cell with a single threaded adapter. During the lightly loaded strut tests, the lower clevis and 50-klb load cell were mounted directly to the hand-operated hydraulic actuator, as shown in Figure 9.

A laser displacement transducer, shown

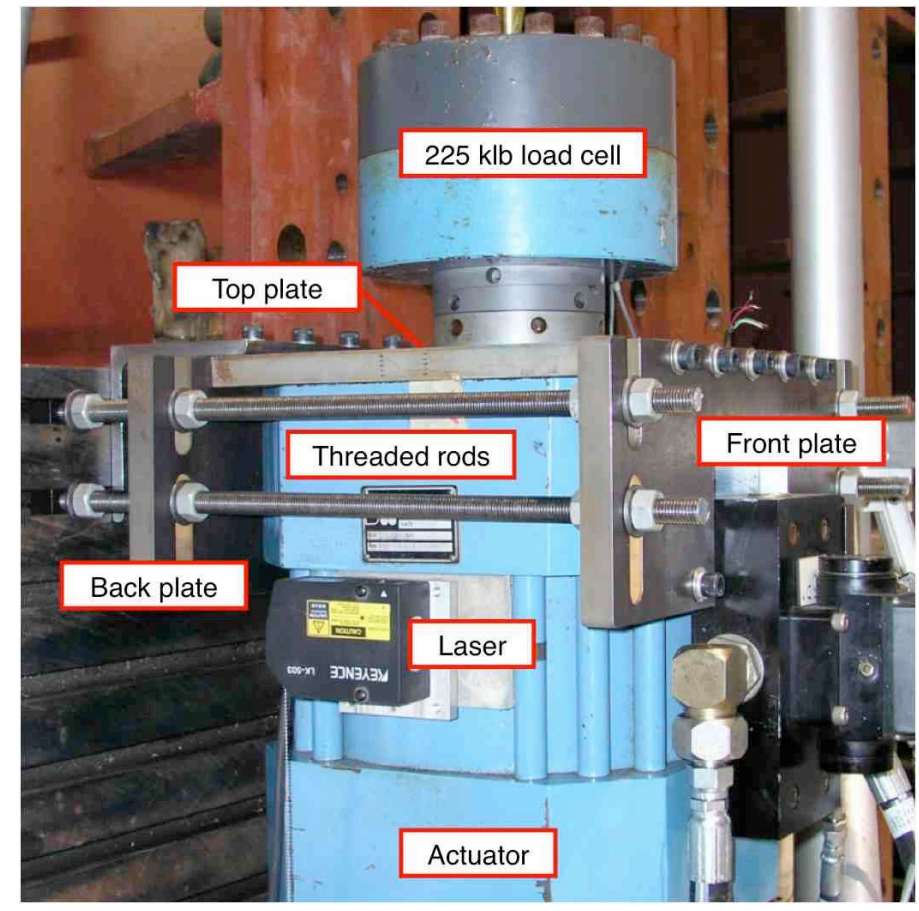

Figure 10. Actuator restraint and alignment hardware. in Figure 10, was also used to measure the actuator motion for displacement feedback and system control. One safety concern that was raised prior to testing was the possibility that this laser signal could be interrupted during load application. This issue was addressed by adding a plastic safety shield around the laser, as shown in Figure 11. Another concern that the high-pressure hydraulic hoses could come loose during actuator operation was mitigated using safety fittings that were specifically designed for restraining hydraulic hoses.

While one goal of the test arrangement was to allow the strut ends to rotate freely, the actuator had to be restrained from rotating as it moved to prevent it from inadvertently applying a torsional load to the strut. To prevent rotation of the actuator piston, the additional support hardware in Figure 11 was built and installed on the actuator. A two-piece yoke was bolted together in place around the actuator shaft, and additional bolts were used to connect the yoke to the actuator shaft. This yoke could then move up and down inside the vertical arms of a guide plate that was bolted to the front plate. This hardware was built to be robust, since it was not known how much torsional load the actuator might

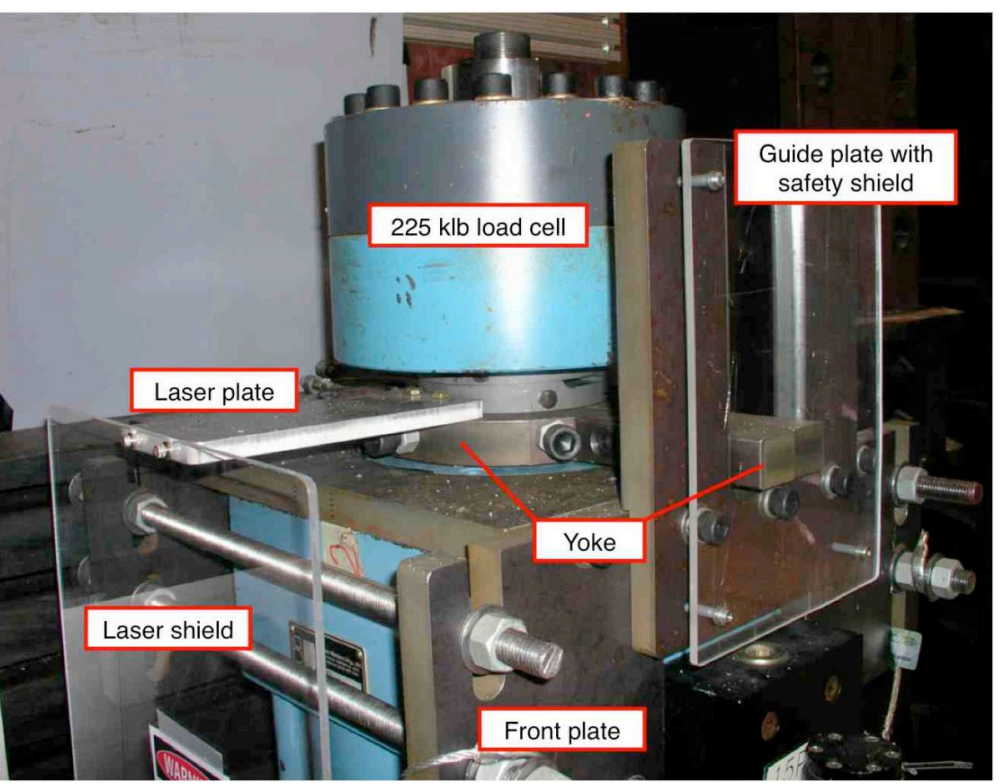

Figure 11. Hardware to prevent actuator rotation. induce into the system. Later examination of wear marks on the yoke and guide plate hardware indicated that these induced moments were low. 


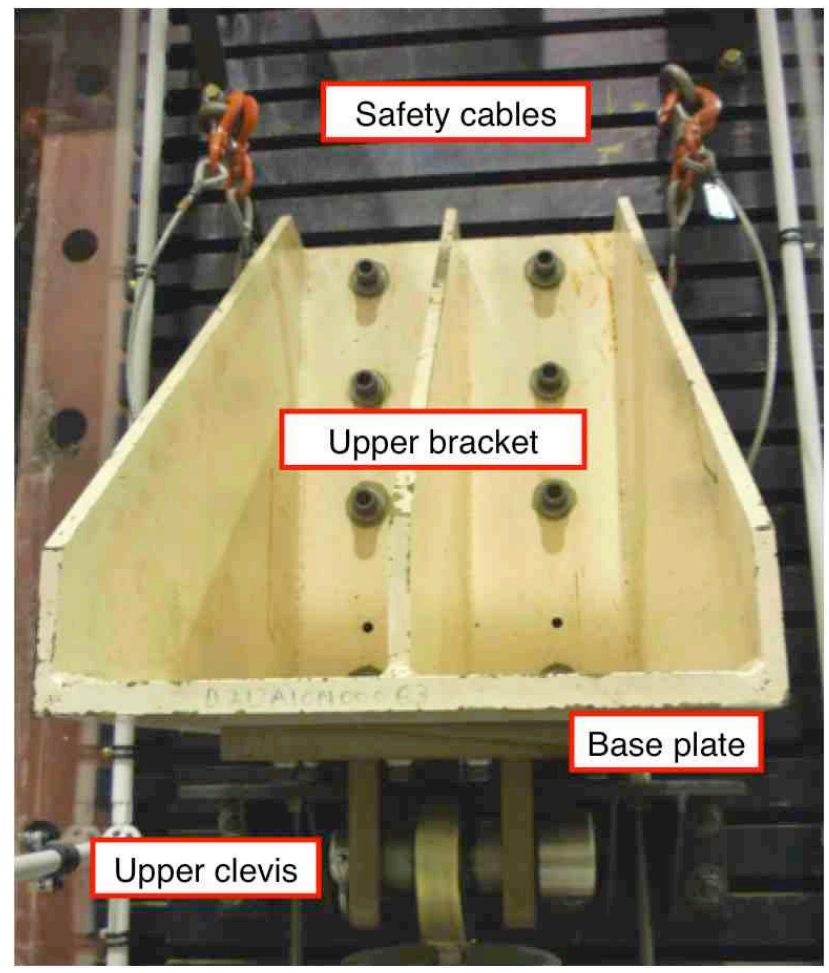

Figure 12. Upper bracket and clevis.

The steel upper bracket, shown in Figure 12, was attached to the backstop using eight socket head cap screws threaded into T-nuts positioned in the backstop T-slots. The upper bracket orientation was also checked with a digital level to verify that it was horizontal. A slotted base plate was bolted to the bottom of the upper bracket. The slots in the base plate allowed extensive front-to-back adjustment, and limited right-to-left adjustment to ensure that the upper clevis could be properly aligned over the lower clevis. This alignment was accomplished by suspending a plumb bob from an alignment hole in the center of the upper clevis base plate, which was then bolted into place when the plumb bob was located directly over a small hole machined into the center of the adapter between the lower clevis base plate and the load cell. The centers of rotation of the upper and lower rod end bearing test fittings were therefore both assumed to be on this vertical line.

Steel cables were installed to connect the upper bracket to the backstop as shown in Figure 12. This was done as a safety measure in case the hardware failed in a way that would allow the entire upper bracket to separate from the backstop. Plexiglass panels, shown in Figure 13, were also positioned around the test column as a safety measure to contain and channel any flying debris from the strut failure. As a final safety precaution, testing was monitored via video camera, rather than allowing direct observation of the test by personnel standing in front of the backstop. 


\section{System Checkout Tests}

System checkout tests were performed to exercise the test hardware, and to evaluate plans and procedures to be applied during the later composite strut tests. Extensive linear and nonlinear finite element analyses were performed to predict the strut structural responses, failure loads and failure modes. ${ }^{2}$ However, since these analyses could only be used as a guide as to when failure was likely to occur during testing, a conservative baseline plan was initially proposed to gradually expand test load levels from a percentage of the design limit load (DLL), then to the DLL, before finally loading to design ultimate load and to failure, while alternating between tension and compression loading directions.

Several aluminum struts were fabricated for the system checkout tests to verify that the test hardware would function as required. A checkout strut is shown installed in the test facility in Figure 13. The wall thickness and diameter of these robust checkout struts were chosen to provide axial stiffnesses that were equivalent to the composite struts, while simultaneously having much higher Euler buckling loads. Internally-threaded aluminum adapters were bolted to each end of the checkout strut tubes. The test fittings described above were threaded into these adapters, and then locked into place with jam nuts. An example of the checkout strut end adapter is shown in Figure 14 . Whenever possible, checkout tests were conducted each time a new strut geometry was tested to evaluate changes in fixturing and controls.

The original lower clevis base plate was manufactured using 1 inch-thick steel plate (see Figure 6a). After the first checkout test with tensile loads of over $30 \mathrm{klb}$ was performed, the lower test fitting was found to be trapped between the spacers and clevis after the steel pin was removed. Close examination of the test hardware revealed that the base plate edges had been pulled upwards by the clevis plates during loading, causing them to rotate inwards and trap the test fitting and spacers. To prevent this undesirable deformation from occurring in future tests, a second base plate was bolted to the original base plate and installed as shown in Figure 15. This reinforcement greatly increased the bending stiffness of the connected plates, and prevented unwanted bending in the later tests.

Measurement of the axial motion of the upper and lower brackets during the checkout tests determined that the upper bracket was sliding relative to the backstop at relatively

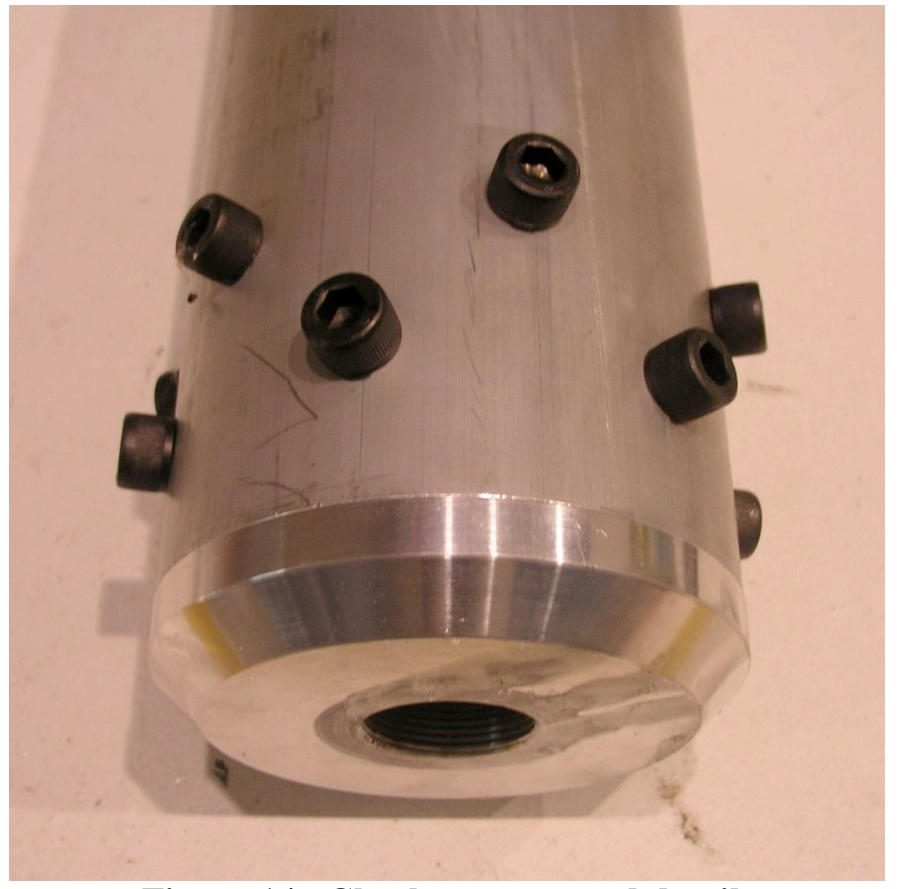

Figure 14. Checkout strut end detail.

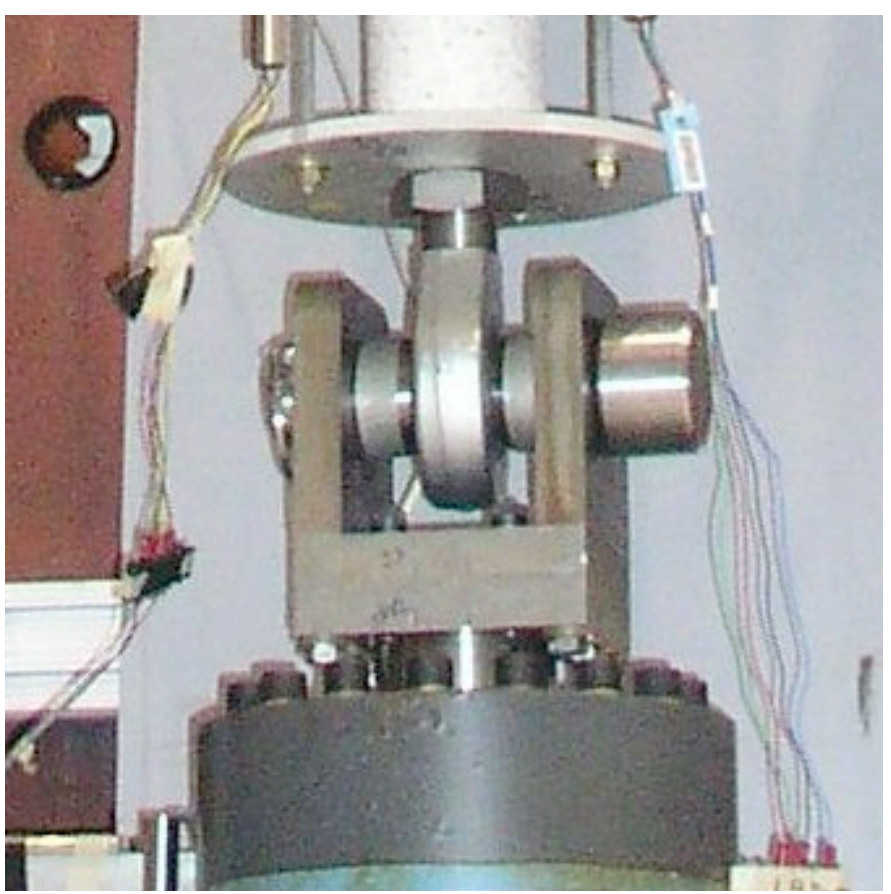

Figure 15. Reinforced lower clevis base plate. 
low loads in both tension and compression. In order to eliminate this unwanted deadband or slippage (i.e., motion with minimal applied load), two jack screws, shown in Figure 16, were bolted to the backstop underneath each corner of the upper bracket, and were preloaded against the upper bracket before each test was performed.

Other sources of possible motion of the upper bracket were the clearances between the existing upper bracket bolt holes and the bolts

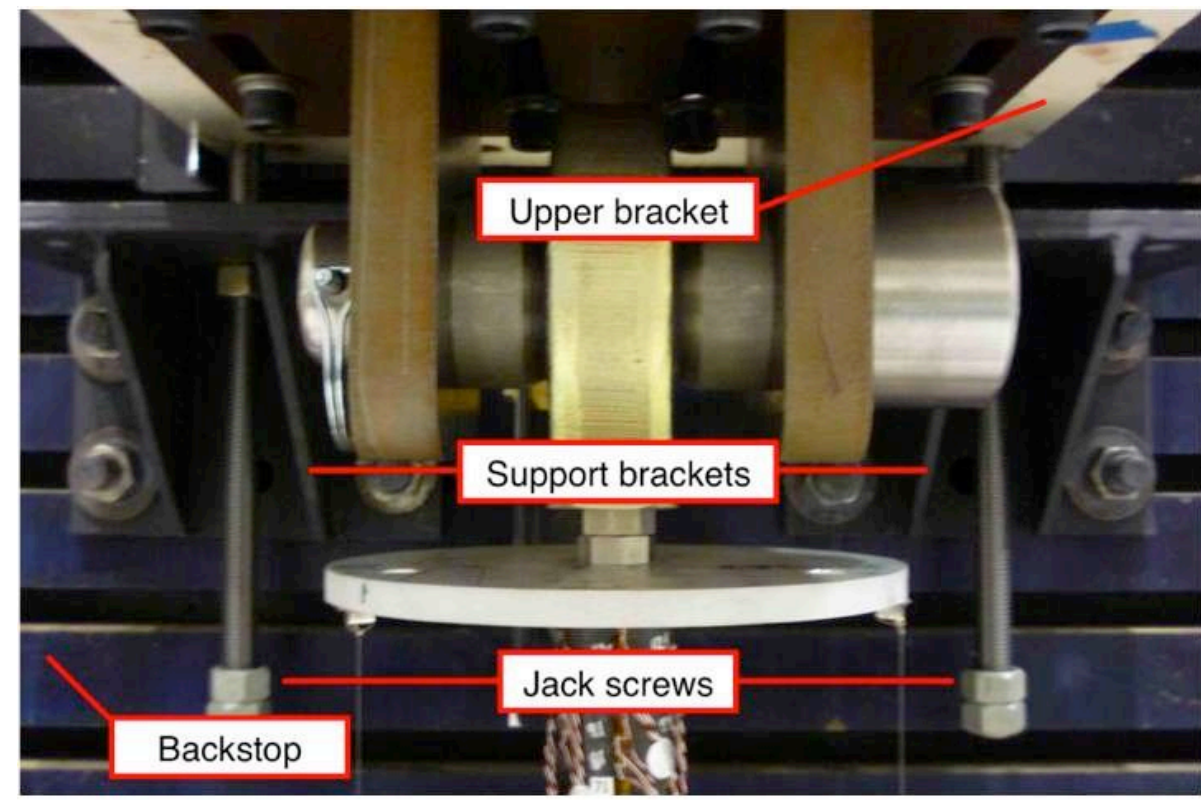

Figure 16. Jack screws. threaded into the backstop T-nuts. To reduce these clearances, conical washers were purchased and machined to reduce the smaller diameter of the truncated cone, as shown in Figure 17. These modified washers then fit better into the upper bracket holes and took up more of the clearance, and thus helped to prevent the bracket from moving as freely around the bolts. This problem arose in part because not all of the T-nuts were threaded completely through. Some T-nuts were only partially threaded to prevent the bolt from passing through the T-nut and damaging the back of the T-slot, so it was important to make sure that the bolt was being tightened against the conical washer and upper bracket, instead of bottoming out into the T-nut.

To further reduce the deadband between the T-nuts and the T-slots of the backstop (shown in Figure 7), the threaded studs shown in Figure 18 were installed. The diameter of these threaded studs were much closer to the upper bracket hole diameter, so they had much smaller clearances in the T-slots. This reduced clearance limited the potential for bolt bending or rotation, but also made them much more difficult to install in the backstop. Therefore, the threaded studs were used to replace only the two lowest, most heavily loaded, bolts at the bottom of the upper bracket. The conical washers described above were installed between the upper bracket and the nuts, and the nuts were torqued on the threaded studs.

These modifications all served to pull the upper bracket tighter against the backstop and reduce the deadband. However, there still appeared to be some movement of the upper bracket at the highest applied loads. The load applied to the column during testing was able to overcome the preload of the bolts connecting the upper

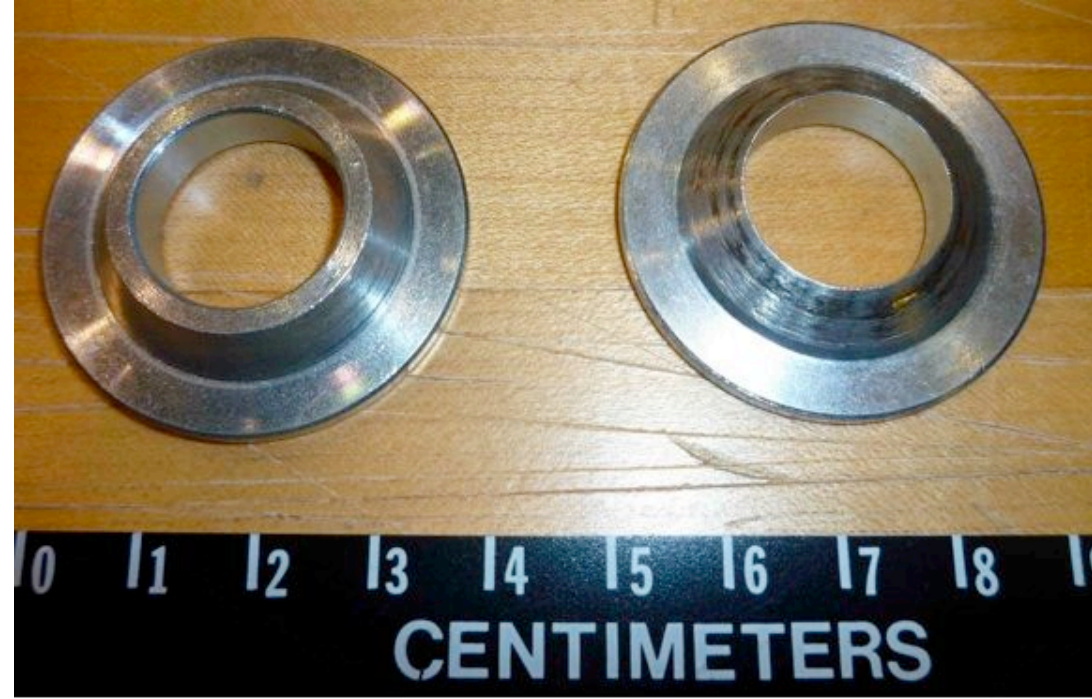

Figure 17. Conical washers (left - original; right - modified). 
bracket to the backstop. This motion (or deadband) would then cease as the hardware clearances were reduced and the fixtures began to take up the loads as originally designed. To further reduce this deadband, the strut test sequence was revised to include a pretest to $30 \mathrm{klb}$ tension (for example) to remove the deadband, followed by the desired tension test load level. Reversal of the load direction into compression would then require another pretest to $-30 \mathrm{klb}$ (thus eliminating the deadband in the other direction) before application of the compressive load.

\section{A. Control and Data System}

For the heavily loaded strut tests, separate personal computer-based data acquisition and control systems were used in the testing. The data acquisition system recorded all strain gage data, LVDT data, load cell data, and laser displacement transducer data. A LabVIEW-based control system was programmed to move the actuator under displacement control. All tests were run in displacement control to prevent damage to the test setup after strut failure. If a test were run in load control, the control system would attempt to continue to increase the load even after strut failure. Initially, this system did not have sufficient internal limit checks, which allowed an operator error to apply sufficient displacement to overload a tuning strut, causing plastic buckling. The control system was

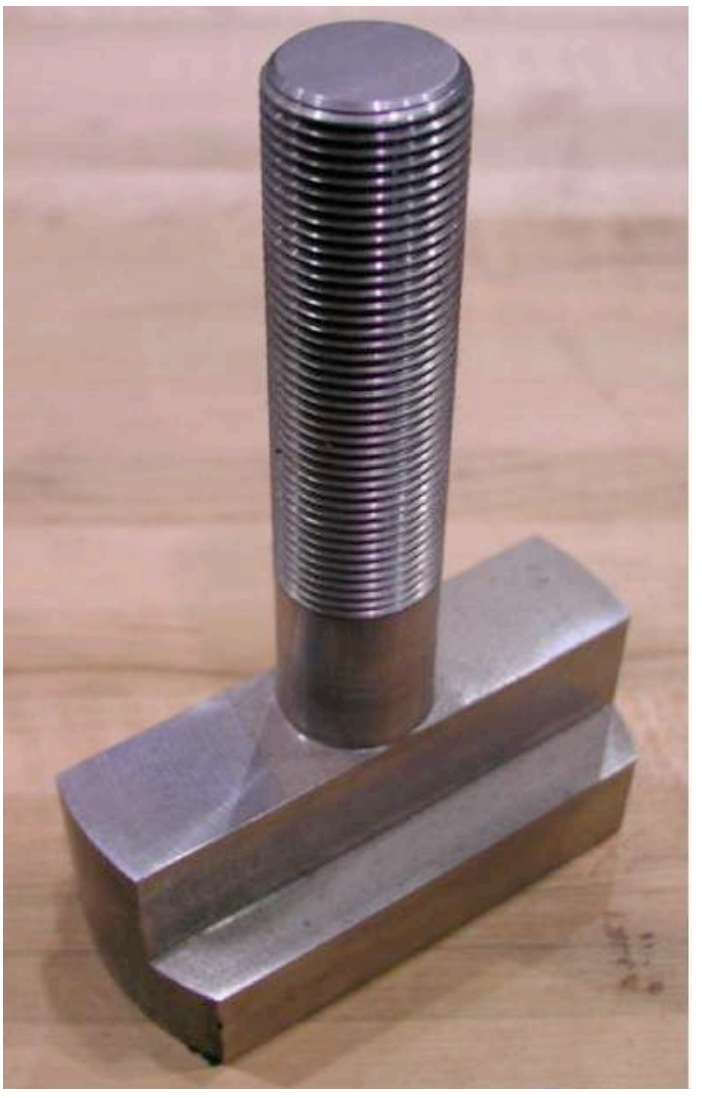

Figure 18. Threaded stud. then modified to better define the allowable load and displacement limits while tuning continued with another checkout strut.

The control system used data from a laser transducer for displacement control of the actuator. However, this arrangement initially did not verify that a signal from the load cell was properly fed to the control computer as displacement was increased. Running the system in displacement control with no load feedback resulted in a large tensile load being applied, which severely damaged the test fittings during one test of a short composite strut. Interestingly, the strut that was being tested was undamaged, and was tested successfully after the test fittings were replaced, and extra checks were added to the control software to make sure the load cells had power.

\section{Composite Strut Tests}

The composite struts shown in Figure 2 were tested in both tension and compression to demonstrate the test capability's readiness for evaluating the struts described in Refs. 5 and 6. Since these struts were fabricated as manufacturing demonstration hardware rather than test articles, they were deemed to be appropriate for this purpose. While tension test results are not presented here, these tests were all concluded successfully with no external indications of failure in the struts or test hardware. Measured displacements and strains from compression tests of the long and one of the short composite struts in Figure 2 are presented and discussed in this section. The long strut, shown during its compression test in Figure 19, buckled elastically at a maximum load of $-103.6 \mathrm{klb}$ into a half-sine wave mode shape. The short strut also buckled elastically at $-27.4 \mathrm{klb}$, which is shown in Figure 20 (note the large lateral deflection at the strut mid-length). Note that these figures are not shown to the same scale. After the applied displacement was released, the struts returned to approximately their untested geometry, with no external indications of failure in the struts or test hardware. 


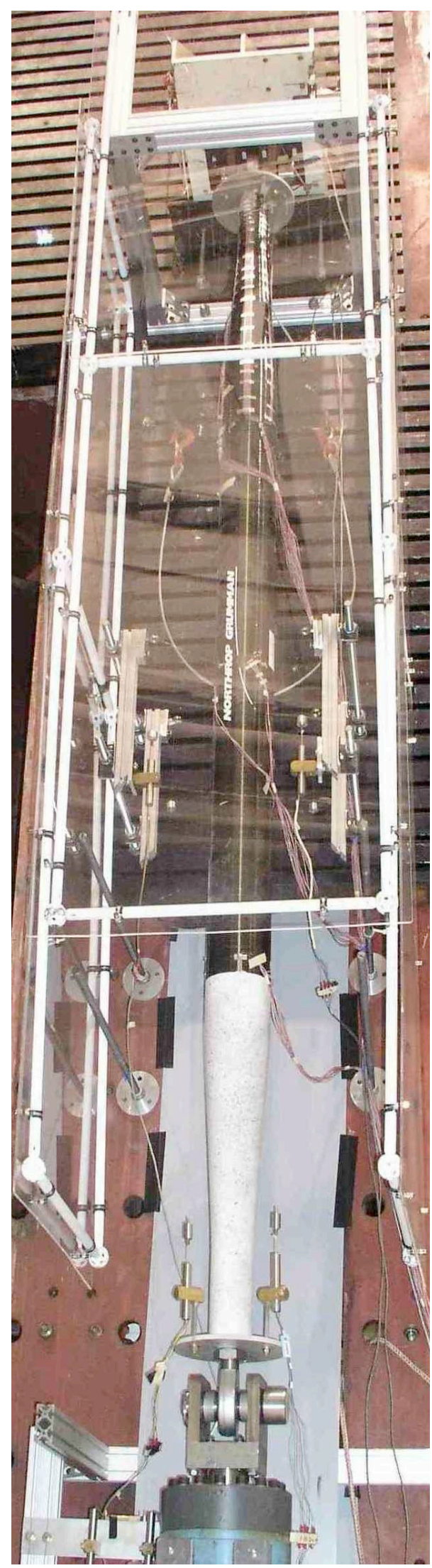

Figure 19. Long strut test.

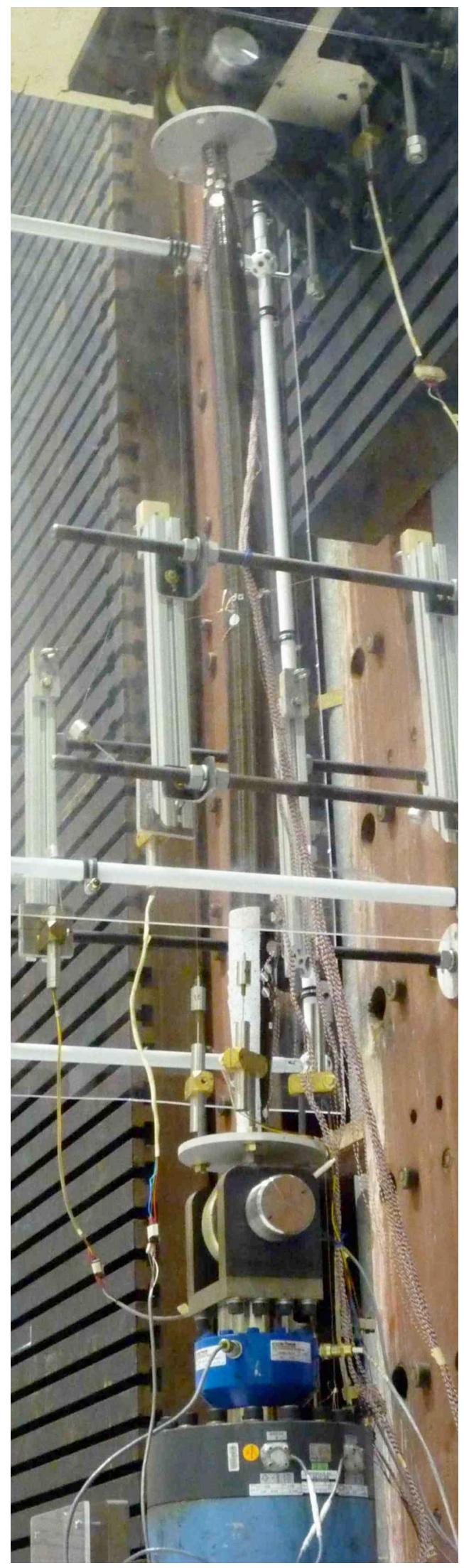

Figure 20. Short strut test. 


\section{A. Displacements}

To evaluate the long strut's structural performance, the measured compressive axial loads are plotted versus the strut axial end shortening in Figure 21. Three end shortening measurements, shown with different colors, were taken around the strut circumference using the LVDTs shown in Figure 6a. The three LVDT measurements were roughly linear up to buckling at -104 $\mathrm{klb}$, and then diverged rapidly thereafter. These trends indicate that relatively little global bending was occurring in the strut prior to buckling. The plotted responses also showed some initial discontinuities at loads below

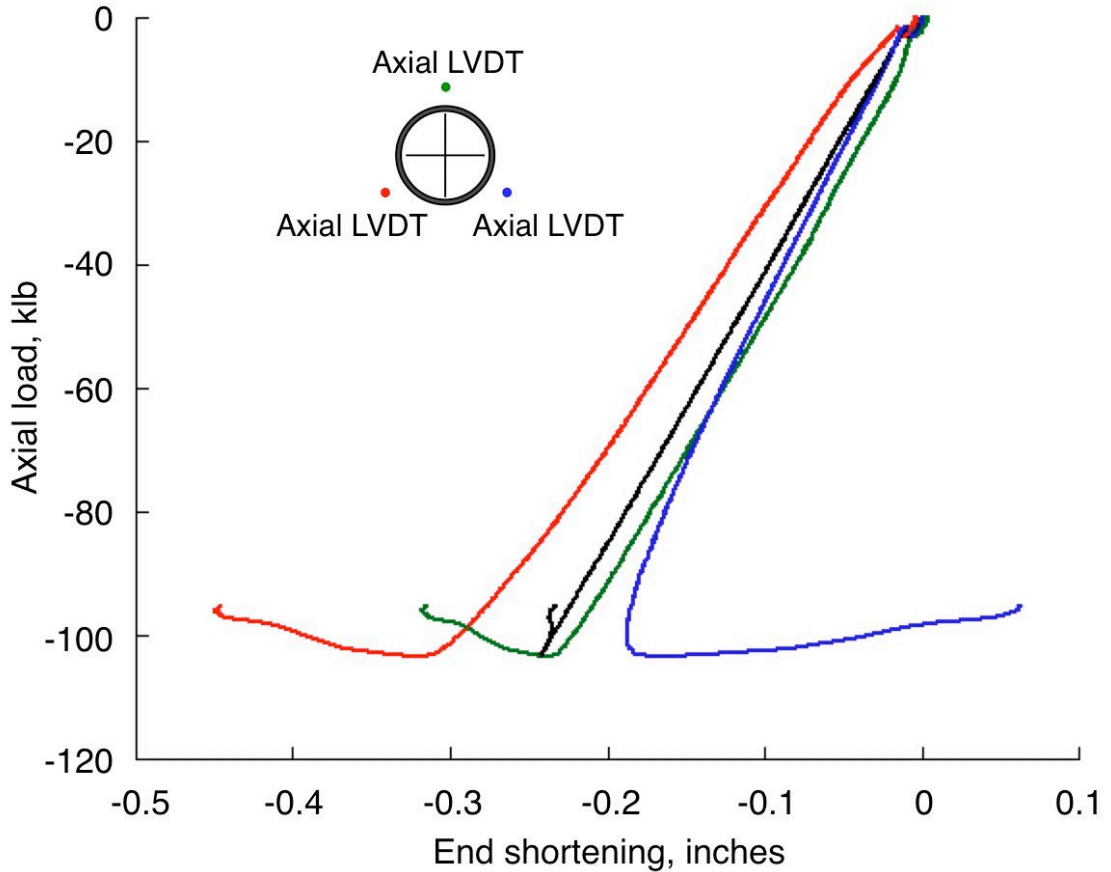

Figure 21. Long strut axial load vs. end shortening. $-5 \mathrm{klb}$. These are thought to be due to internal debonding of the strut end fittings. The overall strut axial stiffness of $439.83 \mathrm{klb} / \mathrm{inch}$ is calculated from the best-fit slope of the linear load versus average axial displacement response, which is shown in the figure as a solid black line.

Two LVDTs were also mounted at right angles to measure the corresponding lateral deflections at the strut mid-length, as shown in Figure 22 for the short strut. The probes of the LVDTs were suspended from monofilament lines attached to the strut, with small weights attached to keep the lines taut as they were turned through 90 degrees. This arrangement was similar to the setup described in Ref. 13. Small balance weights were suspended opposite the LVDTs to counteract the small lateral forces induced by their probes and weights. Larger deflection values are likely not exact in a quantitative sense due to nonlinear geometric effects, but should still accurately represent the qualitative strut motion. The two mid-length lateral deflections for the long strut are plotted against the axial load in Figure 23, along with their vector sum. Positive motion in these

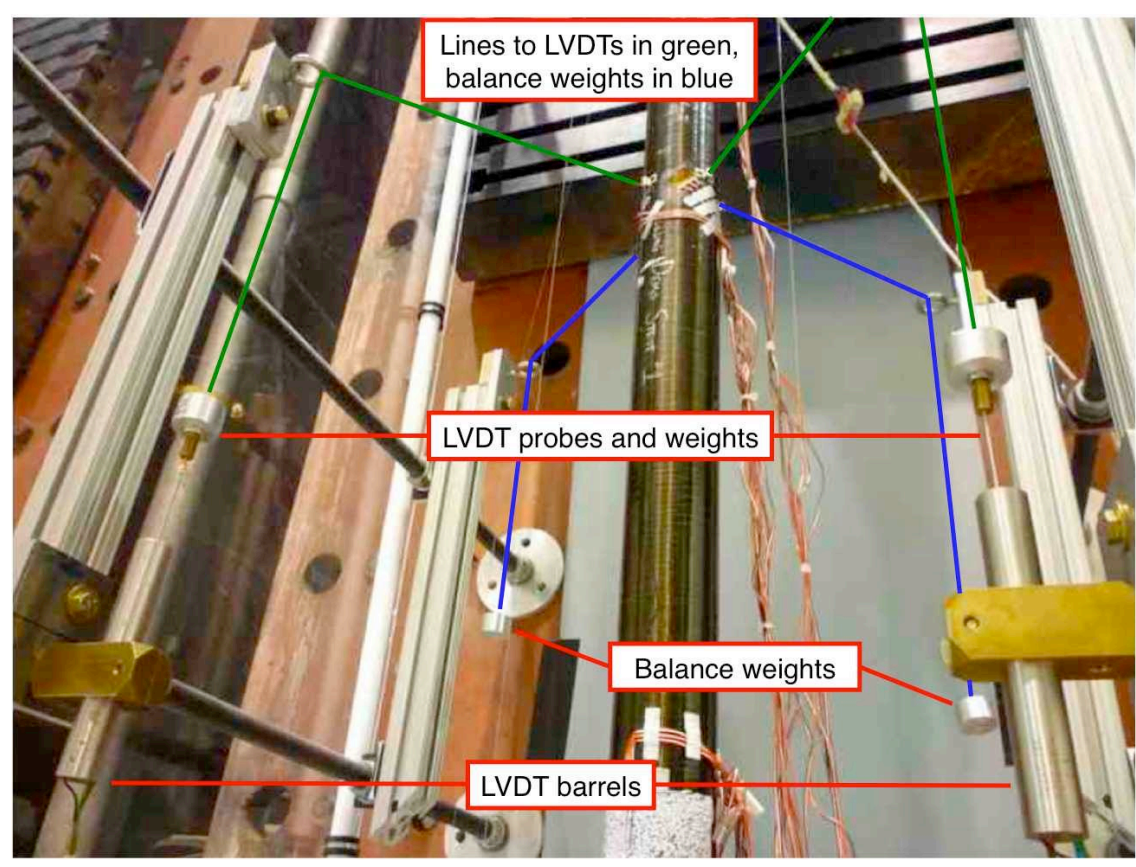

Figure 22. Short strut mid-length LVDT setup. 
LVDTs indicates motion towards the backstop. The near-symmetry of the plotted deflections suggests that the strut was bending in a plane that roughly bisects the two measurements, and was nearly orthogonal to the backstop. The prebuckling ratio of lateral deflection to strut length is approximately $1 / 500$ (or 0.25 inch $/ 125$ inches). This relatively small value confirms the earlier observation that minimal global bending occurred in the strut before it buckled, after which bending increased rapidly.

The measured axial compressive load versus axial end shortening is shown in Figure 24 for the short strut

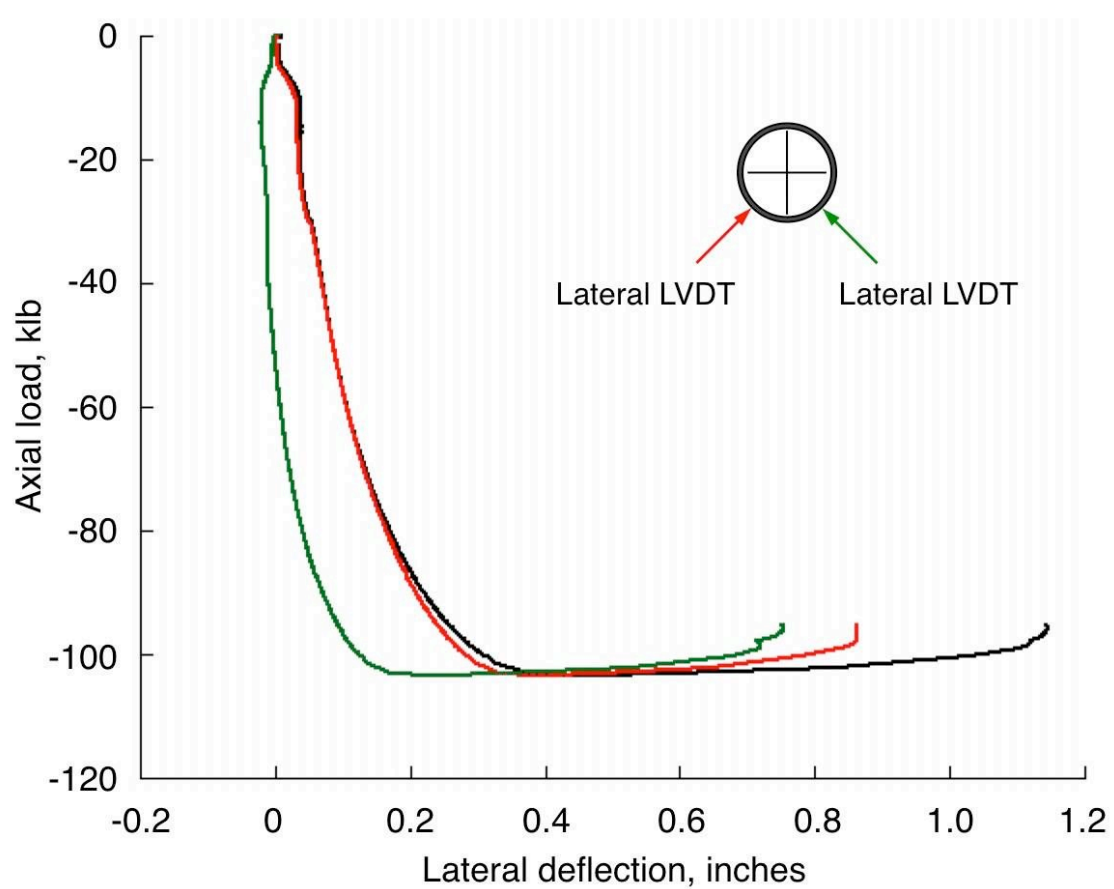

Figure 23. Long strut axial load vs. mid-length lateral deflection.

test. The three individual displacement measurements diverged gradually with increasing load, and then asymptotically approached the $-27 \mathrm{klb}$ buckling load. The large differences between the individual displacements indicated that significant global bending was occurring in the strut before failure, and suggest that this strut had a larger initial geometric imperfection (relative to its length) than the long strut. The overall axial stiffness of the short strut is $254.21 \mathrm{klb} / \mathrm{inch}$, as calculated in the same manner described previously for the long strut. The average axial displacement is shown in the figure as a solid black line.

The measured lateral deflections at the strut midlength are plotted as red and green lines against the compressive axial load in Figure 25. The vector sum of the two individual mid-length lateral deflections, shown in the figure as a black line, is hidden by the red deflection trace. The asymmetry of the plotted deflections suggests that effectively all of the strut bending was occurring in a plane that contains only one of the two measurements. When considered with the data in Figure 23, these results demonstrate that the test fittings developed here did not force the strut to buckle in a specific

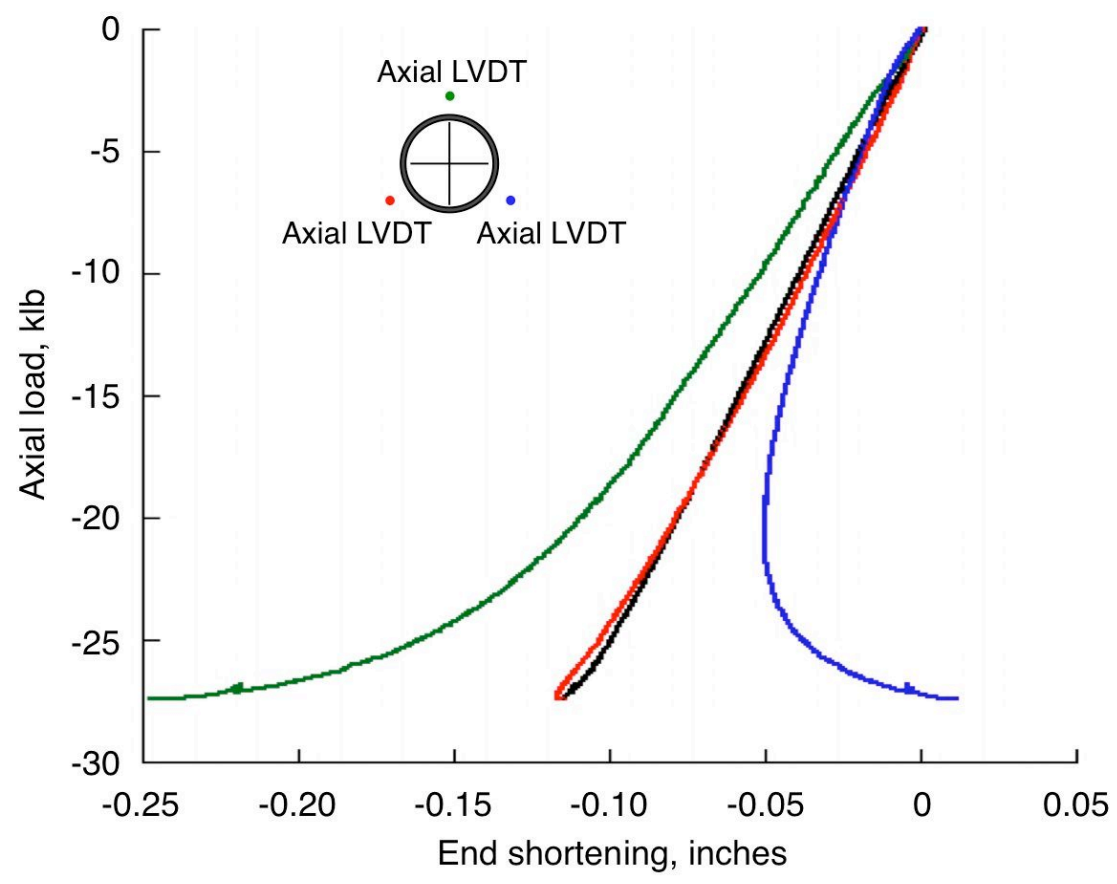

Figure 24. Short strut axial load vs. end shortening. 
orientation with respect to the clevis pins. The high prebuckling ratio of lateral deflection to strut length of roughly $1 / 120$ (or $0.5 \mathrm{inch} /$ 60 inches), is indicative of significant global bending before buckling of the strut, again likely due to its relatively large initial geometric imperfection.

\section{B. Strains}

The compressive axial load applied to the long strut is plotted against the midlength axial strain in Figure 26. Three separate strain measurements, denoted with the different colors, were recorded at locations equally spaced around the strut circumference. The average

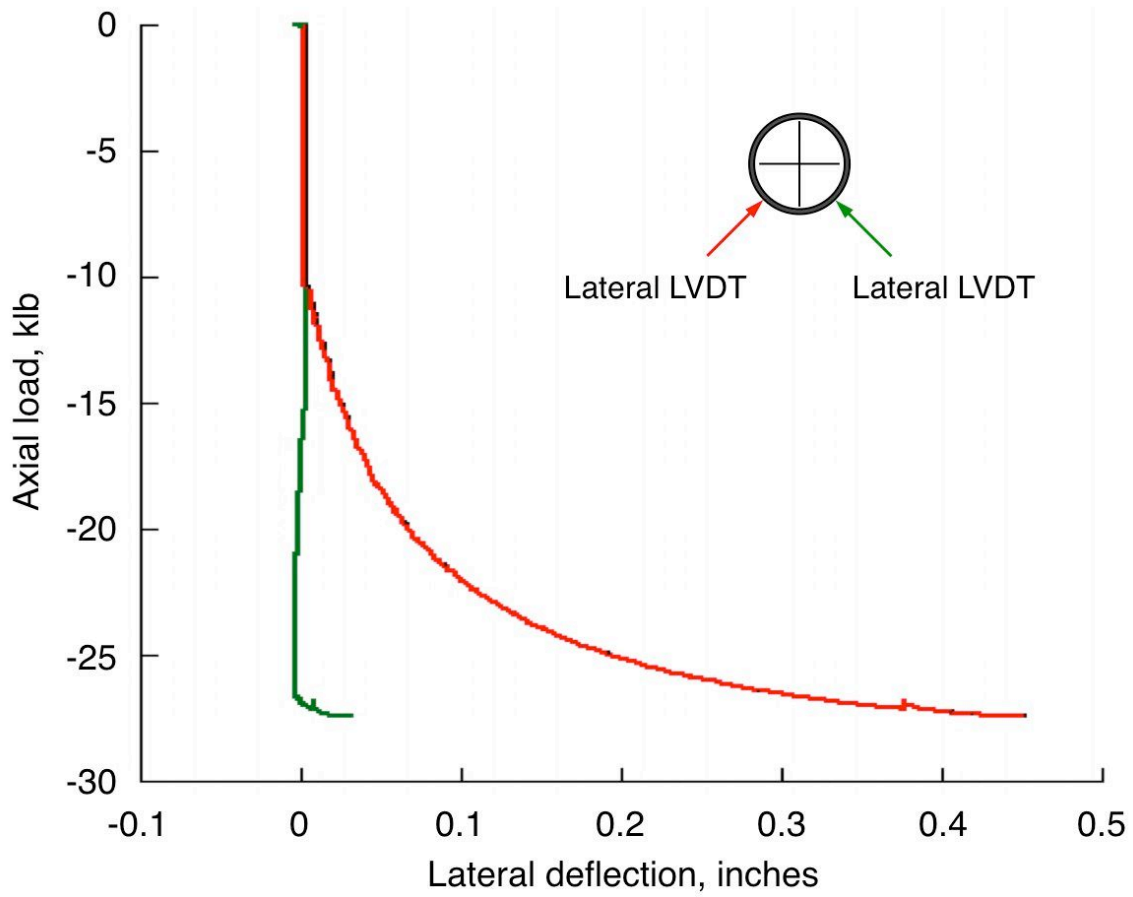

Figure 25. Short strut axial load vs. mid-length lateral deflection.

slope of the load versus the linear average axial strain (shown as the solid black line) is equal to 47.65 Mlb. This value represents the cross-sectional axial stiffness at the strut mid-length, which is the product of the strut cross-sectional area and the effective axial elastic modulus of the laminate. Subtraction of this average strain from the three individual measurements gives the bending strain components, which increase from zero, to about \pm 25 percent of the average axial strain at buckling. This result can be contrasted with the strength-based strut failure described in Ref. 10, where the bending strains are bounded within about \pm 5 percent of the axial strain through failure.

The strut compressive axial load is then plotted against the mid-length axial strain in Figure 27 for the short strut. The average slope of the load versus the linear average axial strain is shown in the figure as the solid black line, and is equal to 15.14 Mlb. The computed bending strains all increase from zero up to about \pm 50 percent of the axial strain when the strut buckles. The larger contribution of bending to the structural response of the short strut may be a result of its larger initial geometric imperfection.

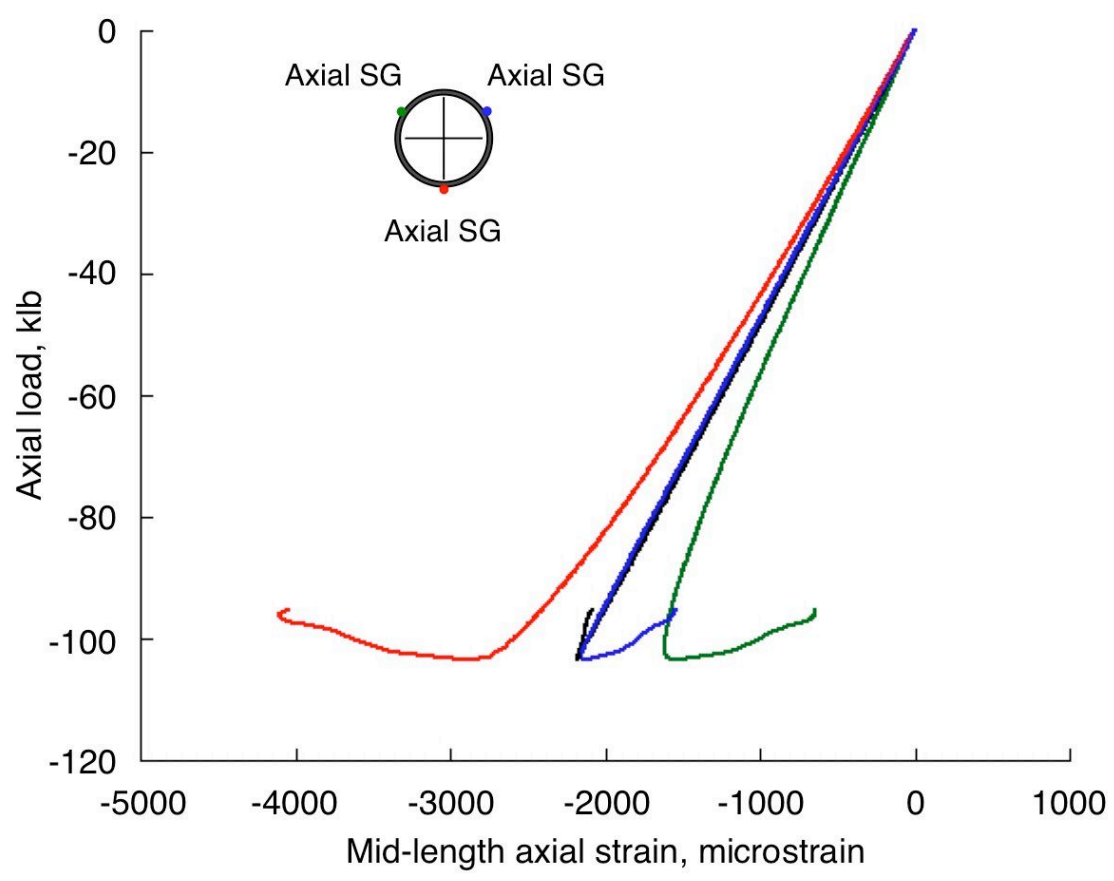

Figure 26. Long strut axial load vs. mid-length axial strain. 


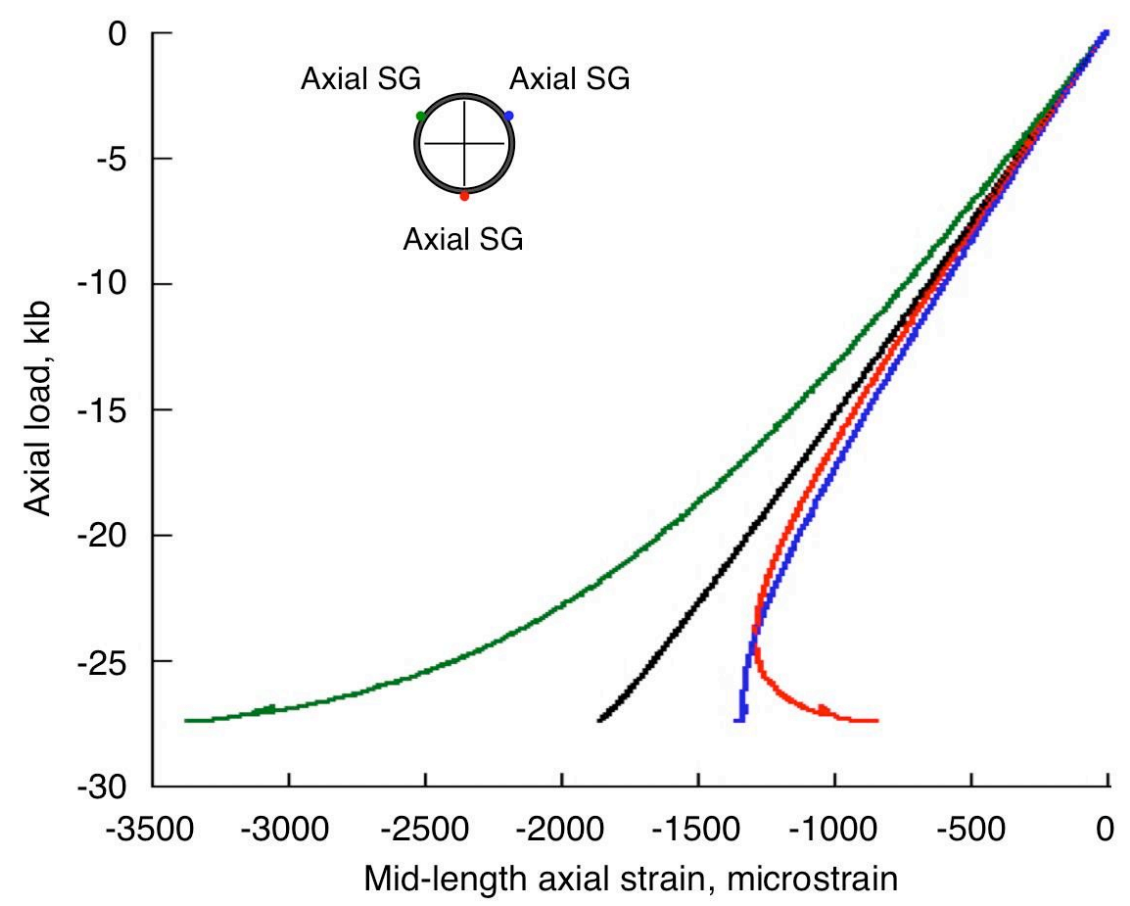

Figure 27. Short strut axial load vs. mid-length axial strain.

\section{Concluding Remarks}

An experimental approach for subjecting long tubular struts to tensile and compressive loadings was developed and is described herein. Fixtures simulating pinned end conditions were fabricated and appeared to function as designed. Important features of this test arrangement included the use of conical washers to minimize fixture slippage, and preloading the struts to minimize the deadband region. The capability to test large, heavily loaded composite struts was developed and successfully demonstrated at compression loads of over $-100 \mathrm{klb}$. The test fitting design selected was shown to successfully replicate the theoretical, pinned-end boundary conditions necessary for Euler buckling, which can be very difficult to achieve experimentally. This test capability was then used to successfully test several heavily loaded composite struts developed under NASA's Advanced Composites Technology program. Slender, more lightly loaded struts were also successfully tested using a similar capability.

\section{References}

${ }^{1}$ Draper, R., "Advanced Composite Structures and Materials Technologies for Launch Vehicles," Proceedings of the 2010 National Space and Missile Materials Symposium, Scottsdale, AZ, 28 June-1 July 2010.

${ }^{2}$ Jegley, D. C., Wu, K. C., Phelps, J. E., Oremont, L. and McKenney, M. J., "Structural Efficiency of Composite Struts for Aerospace Applications," Proceedings of the 52nd AIAA/ASME/ASCE/AHS/ASC Structures, Structural Dynamics and Materials Conference, Denver, CO, 4-7 April 2011.

${ }^{3}$ Anon., "NASA's Exploration Systems Architecture Study: Final Report," NASA/TM-2005-214062, November 2005.

${ }^{4}$ Collins, T. J. and Nienaber, T., "Altair Lunar Lander: Design and Analysis Cycle III Structures and Mechanisms Design Summary," presented at the NASA Johnson Space Center, Houston, TX, 25 June 2010.

${ }^{5}$ Messinger, R., "Design and Manufacture of Structurally Efficient Composite Struts - Concept 1," final report for NASA contract NAS NAS1-NNL04AA11B, Task NNL09AC35T, 2009. 
${ }^{6}$ Pires, K., Benner, H., Deo, R., Grover, R., Palm, T., McLaughlin, M., Olason, E., Lucking, R. and Collier, C., "Design and Manufacture of Structurally Efficient Composite Struts - Concept 2," final report for NASA contract NAS NAS1-NNL04AA13B, Task NNL09AC36T, 2010.

${ }^{7}$ Messinger, R., "Design of Structurally Efficient Tapered Struts," NASA/CR-2010-216698, May 2010.

${ }^{8}$ Deo, R., Benner, H., Vincent, D., Olason, E. and Harrison, R., "Design of Structurally Efficient Tapered Struts (SETS)," NASA/CR-2010-216699, May 2010.

${ }^{9}$ Jegley, D. C., Wu, K. C., Phelps, J. E., McKenney, M. J., Oremont, L. and Barnard, A., "Evaluation of Long Composite Struts," NASA/TM-2011-217049, February 2011.

${ }^{10} \mathrm{Wu}$, K. C., Jegley, D. C., Barnard, A., Phelps, J. E. and McKenney, M. J., "Highly Loaded Composite Strut Test Results," Proceedings of the 32nd SAMPE Europe International Technical Conference and Forum, Paris, France, 28-29 March 2011.

${ }^{11}$ Timoshenko, S. P. and Gere, J. M., Theory of Elastic Stability, McGraw-Hill Book Co., Inc., New York, 1961.

${ }^{12}$ Lake, M. S. and Georgiadis, N., "Analysis and Testing of Axial Compression in Imperfect Slender Truss Struts," NASA TM-4174, February 1990.

${ }^{13}$ Lake, M. S. and Wu, K. C., "Preliminary Investigation of Stability of a Fin-Stiffened Slender Strut," NASA TM-4034, April 1988.

${ }^{14}$ Watson, J. J. and Phelps, J. E., "Inflatable Tube Characterization - Mechanics Testing and Results," presented at the NASA Langley Research Center, Hampton, VA, 17 October 2000. 